\title{
The impact of relational and functional customer-centered of sales force on the success of new product development (Intervention variables: Transformational Leadership, Interdependence with Sales Unit, Customer Behaviorism)
}

\author{
Alireza Mohammadkhani ${ }^{1}$, Zeinab Jaripour ${ }^{2}$ \\ ${ }^{1}$ MA in Marketing Management. \\ ${ }^{2}$ MA in Education Management. Jaripour61@gmail.com
}

ARTICLE INFO
Keywords:
Functional customer
centered, Relational
Customer-centered,
Product development
process

\section{Introduction}

At the present time, the right to choose customers is wider than ever, and therefore, economic firms have to pay more attention to the needs and interests of their customers. Since marketing is a science of success in attracting and retaining customer in competitive markets, various industry

*Corresponding author E-mail address: a_mohammadkhani@barijessence.com 
executives are trying to ensure their success more than ever through the application of marketing principles and, of course, fully understanding the concepts of marketing and its proper application can be used to improve the competitive position of economic firms. Accordingly, paying attention to the obvious and hidden needs of key customers can lead to the design and delivery of appropriate goods and services. Obviously, any organization will do better in this regard, it will achieve more success. The purpose of this study is to investigate the effect of relational and functional customercentered sales force on the success of new product development.

\section{Statement of problem}

After many years, human knowledge and experience concluded that in order to achieve the goals, meet the needs, problems and, ultimately, the overall progress, human societies need the organization in all fields of economic, political, social, educational, cultural, security and like them. Organizations need new ideas, thoughts to continue to play a positive and constructive role in order to ensure their dynamism through new perspectives based on field research, and ideas and theories otherwise they will be destroyed. Resistance of organizations to global and regional changes caused them to be eliminated and they will not even be able to maintain the status quo.

Müller and Lekarman (2011) have shown that the seller cannot participate in two types of customer- centered (relational and functional) during customer interactions. Functional customercentered and relational customer-centered with applied orientation of customer and task-like has engaged task-oriented sales practices to help solve business problems of customer. Creativity is inherent desire in human being and man is the manifestation of divine creativity (Motahari, 1993). Global transformations in the field of science and industry have forced human societies to seek to increase their ability to cope with these changes, with a new approach to non-objective assets. In fact, the stagnation and immobility in the changing world, whether for an organization or for a country of any size, will have no result but destruction. Today, creativity and innovation are not considered as a requirement, but as a condition for the survival of any organization or society, and has been emphasized on training and acquiring the skills necessary to utilize this particular human talent. (Khoshnevis, 2008).

Today, the pharmaceutical industry is one of the important industries that organizations and financial and human resources are working in this regard. Today, the pharmaceutical world has found that it should spend a significant amount for pharmaceutical and marketing costs from the place of production and sale of medicines in order to improve the level of specialized knowledge and prescription of drugs, as well as increase the efficiency and level of customer satisfaction. Typically, 12 leading pharmaceutical companies in the world spend 34 percent of sales of their products to update specialized knowledge and prescribe drugs by doctors and pharmaceutical marketing per year. In fact, drug information is important in the pharmaceutical industry, and pharmaceutical companies pay special attention to this issue. Because the pharmaceutical information through various methods rationalizes and prescribes scientifically and rationally drugs for patients by doctors, it also increases the effectiveness of drugs in treating patients and ultimately increases the level of customer satisfaction. (Economy world, 2013). In this regard, this research has been conducted to investigate the impact of functional and relational customercentered of sales force on the success of the new product development.

\section{Defining customer-centered}

The concept of marketing is based on a perspective from outside to inside and it begins with a proper definition of the market, focuses on the needs of customers, integrates all activities that 
affect customers, and creates profit by satisfying customers. This concept leads organizations towards customer-centered. (Katler, 2010).

By a review on marketing history, it is worth noting that companies, especially business firms, have moved from various marketing orientations towards customer-centered marketing and customer-centered attitude. In the 1950s, companies realized that instead of convincing people to buy what they were producing, they had to produce what people wanted to do, which led to the emergence of marketing orientation (Bose, 2002).

Before 1990, the focus of many companies was on trading with customers. But since 1990, many companies focused on aspects such as how to maintain positive relationships with customers, how to increase customer loyalty and how to change the value of customer's durability. (Ahn, 2003).

Kordnaeich considers customer-centered as collecting information about the customer and using this information in business units. In business environments that competition is intense there, customers have the power to choose, and there are several ways in front of them that can be used to meet their needs. In such a situation, it should be more sensitive to the needs of its customers in order to meet these demands better than competitors. Otherwise, due to the intense competition in the market, the customer will be lost. (Kordnaeich, 2004).

Kim et al. considered the customer-centered as the customer's perception of meeting his wants and expectations (assessing how much the customer feels to meet their expectations). (kim et al, 2004) Augusto, Coelho have defined the customer-centered collection of customer information and use of this information in business units. (Augusto, Coelho, 2009)Strong and Harris have defined the customer-centered as a kind of organizational culture that, in the most effective and efficient form, creates the necessary behaviors to value the customers in the best possible way. (Strong and Harris, 2004)Auh and Menguc have defined customer-centered the tendency to obtain information about the customer and use them in formulating and implementing a strategy to respond to customers' requirements and needs. (Auh and Menguc, 2007).

\section{Philosophy of customer-centered}

By entering the third millennium, many of the concepts in the leading organizations have found other meanings and, consequently, have undertaken a new role in societies. The customer's term has not been safe from this transformation, since its concept doesn't provide a commercial deal, but today human relationships find concept in a mutually interaction. So that each person is on the one hand, the customer of other people and on the other hand, he has customers. Nowadays, the role of customers has shifted from following the producer to the direction of investors, producers, and even researchers and innovators. In this way, many of the concepts and theories are written on the customer's axis. The direction of all the activities of the economic firm is to meet the needs of the customer and to obtain his satisfaction and trust. Also, in today's mass market, the success or failure of an economic firm depends on customer behavior. It is the only customer who studies and examines his needs and the vast market and the various goods and, according to his capabilities and talents, he chooses to value such things as price, quality (Kordnaeich, 2004).

Focusing on the needs of customers means paying attention to quality and serving customers, so each organization strives to be customer-oriented. Service organizations have discovered that they have to satisfy customers in order to achieve their goals or to overcome them. Because neglecting customer satisfaction, which results from neglecting its needs is similar to their failure (Brown et al, 2002).

The concepts of organization's success and customer satisfaction are very close. Since customer satisfaction is one of the key factors of success, it can be concluded that in order to achieve success, 
the organization must have satisfied customers and to have such customers, it should improve the quality of service throughout the organization. As a result, managers should behave well with human resources in order to improve the quality of services in the organization. Research shows that $96 \%$ of customers never complain about bad behavior and the poor quality of goods and services, and $90 \%$ of those unsatisfied customers do not go back to the company. Each of these unsatisfied customers transfers their discomfort to at least 9 people. And $13 \%$ of unsatisfied customers transfer their dissatisfaction to more than 20 people (Nazarmand, 2011).

\section{Transformational leadership}

Transformational leadership theory, first introduced by Burns (1978), to distinguish between those leaders who have strong and motivational relationships with subordinates and followers, and those who are widely focused on exchanging or interacting to produce results. He determined that a transformational leader is looking for potential motives in followers and meeting their higher needs. Transformational leaders establish a mutually motivational relationship that transforms followers into leaders. Therefore, transformational leadership is interactive and mutual. (2004 Duckett, Macfarlane,)

Bass and Avoliyo have defined the transformational leadership as a leadership when it happens it stimulates an incentive among colleagues and followers to investigate their work from a new perspective. The transformational leader creates awareness from the mission or vision of organization and develops colleagues and followers for higher levels of ability and potentiality. In addition, the transformational leader encourages colleagues and followers to consider interests that profit the group. The impact of transformational leadership on the staff of the organization is as follows:

A-Individual considerations: Individual considerations associated with transformational leadership behaviors related to behave with individuals is as important contributors to the work environment. Leaders using this leadership style show considerations for the needs of their employees and are ready to encourage the development of appropriate work environment.

B-Inspiration motivation: Increasing employees' awareness about mission and insight of organization and encouraging others to recognize and commit to them is the main aspect of the inspirational motivation of transformational leadership. Inspiration motivation investigates the principle of organizational existence, rather than the leader's personality. Leaders who use inspirational motivation as leadership behavior have transmitted their ideas and insights to their employees in clear ways, encouraging employees to develop beyond standards, and thus grow and develop themselves and the organization.

C) Intellectual stimulation: leaders who rationally stimulate employees encourage creativity and acceptance of challenges as part of their work. They apply methods of dealing with problems in a rational behavior.

D) Ideal impact: Ideal impact is a behavior that encourages followers to use their leaders as a model. Another term used to describe this form of leadership is charisma. At center and core of the ideal effect, there is the creation of values that are inspirational and meaningful and create sense of purpose in people. Leaders with high ideals have a strong sense of emotional control stability as well. They believe that changing their followers through communication, role modeling 
and encouragement are the right strategies for achieving the mission and goals of the organization. In short, the main indicators of ideal effect are: modeling, creating and explaining values, important and meaningful, sense of purpose, trust and confidence to followers, self-esteem, sense of emotional control and self-determination. (Santora, Sarros, 2001)

Bose suggests a hypothesis that transformational leaders are more likely to be viewed as more effective and satisfying leaders by testing multi-factor leadership questionnaire across the private and public sector. His findings show that transformational leaders have made better relations with their supervisors and their followers than interacting leaders, helping more to organization. In addition, he found staff more willing to work more and raise standards for transformational leaders. Focusing on individual considerations means that transformational leadership leads to more risk taking and high levels of entrepreneurial activity. When a company is faced with turbulent market, transformational leadership needs to be expanded at all levels of the company. (Duckett \& Macfarlane, 2003)

Bose argues that transformational leaders have access to higher levels of success in the workplace than interactive leaders. Transformational leaders, in contrast to interactive leaders, are more likely to develop and deliver better financial results. He also observed that staff has ranked transformational leaders more satisfied and more effective than interactive leaders. (Bose, 2002).

\section{The concept of creativity in the organization}

Creativity means presenting a new idea and plan for improving the quantity or quality of the organization's activities (improving performance), such as increasing productivity and products or services, reducing costs, improving methods and providing new services that are usually directly related to creativity and productivity and increases the level of employee performance in an organization.

Creativity is the desire to create work and production that is potentially in all individuals and in all ages and is closely related to the social and cultural environment. In appropriate conditions, it is necessary to this natural tendency to be realized itself. In other words, creativity means the creation of new and valuable achievements, based on a kind of thinking that is more or less common in all individuals. Creativity is the ability of a person to create ideas, theories, insights, or the production of new goods and rebuild in science and other fields that are considered by experts as an innovative and scientifically aesthetic, technological and social phenomena with value.

The organization can achieve the goal of greater productivity by solving the problems associated with each of the cases presented with the changes introduced into the system. In some cases, creativity is to achieve innovation and increase efficiency and effectiveness (human resource productivity) and can lead the organization to move towards global changes coherent and consistent with national development. However, the creativity is considered employing mental abilities to create a new thought or concept. (Mirzaie, 2011).

Organizations are divided into four groups according to the amount of attention and emphasis on development, along with changes in the environment and creativity. Organizations that pay attention to the development and environmental changes and are innovative and in terms of creativity, are in high level, it means that they investigate creativity and follow innovation for response to changes in the environment. In contrast, these organizations are the second group that are weak in terms of development and change, and in terms of creativity, these organizations remain conservative and traditional, not creative, not innovative. The other category is the organizations that are focused on development and change, but because they are not creative, they imitate to respond to their own environment, and make innovations. The latter category is a very 
creative organization that not emphasizes on development and change. This group of organizations deals with creativity and presents new theories, but because they do not need for practical innovation, they neglect innovation and their ideas are not applicable. (Alvani, 1994).

\section{Stages of new product development}

1. Idea generation: The creation of a new product begins with the search for new ideas. The successful company should create many ideas to create new products from them. 2- Refinement of ideas: At the stage of creating the idea, the goal is the creation of new ideas, while in the later stages; the goal is the reduction of number of ideas. The first step in reducing ideas is to refine ideas. In this stage, the company must avoid two types of mistakes: the first mistake occurs when it rejects a good idea.

3- Development and testing of the concept: After refining the ideas, they must be converted into product concepts. The distinction between product idea, product concept and image or mentality of product is very important. In fact, the product idea is about the product that the company thinks that it can be supplied to market. The concept of a product is a detailed description of the idea, which is expressed by understandable phrases for customers. The image or product mentality is the visualization and perception that consumers have about the product.

4. Development of marketing strategy: The next step is the development of a marketing strategy for introducing the product to the market. The marketing strategy consists of three parts:

The first part of the marketing strategy is about the size, structure and behavior of the market; the positioning for the product, the sales review, and the determination of the profit in the first few years.

The second part of the marketing strategy is to determine price, production, distribution strategy, and marketing budget for the first year.

The third part of the marketing strategy is to predict long-term sales and determine profit goals and marketing mix strategy over time.

1- Business review: After deciding on the concept of product and marketing strategy, management can evaluate the proposed commercial performance. He must determine the amount of sales, costs and profits, whether we achieve the goals of the company. If the answer is yes, it can be developed the product.

2. Product development: If the concept of the product passes through the commercial review process, it must be given to the $\mathrm{R} \& \mathrm{D}$ or engineering section for conversion into a physical product. Until this stage, everything was in the form of word, image and imagination. Thereafter, it is considered a huge leap in investment, and if there is a mistake in estimating the cost of a new product, there will be a lot of damage to the company in the future. At this stage, it becomes clear that the product idea can be turned into a physical and commercial product. If the answer is no, the company loses the capitals that has been spent on the idea so far, unless it gains useful information through the process. The research and development section makes one or more physical examples of the product. When constructing this sample, the following criteria must be met:

1. Customers find product including the features that are in the product concept.

2. The sample should be easily used in normal conditions.

3- It should be made in accordance with production costs.

1) Market testing: At this stage, product testing and marketing plans are implemented in real market situations. The market test allows the marketer to gain experience in marketing the 
product and to solve the potential problems and defects, and obtain the information required before entering the stage of product introduction to market.

2-Trading: Market testing is likely to provide management enough information to make a final decision on whether a product enters the market. If the company wants to trade the product, it will face a lot of costs. (Entrepreneurs Comprehensive Information Base, 2015).

\section{Research background}

Fakhredini and colleagues have investigated the impact of customer participation in the development of a new product in Yazd tile and ceramic industries. The purpose of this research is to investigate the effect and importance of customer participation on the new product development. The variable of technology uncertainty is one of the factors influencing customer participation, which has been studied from two dimensions. Another dimension that has been identified and investigated as the intermediate variable of customer participation and the new product development is operational outcomes that have two variables of innovation speed and technical quality. (Fakhredini and colleagues, 2017)

Seyyed Bagheri has conducted a " study of the relationship between customer-centered and financial performance of the company according to the mediating role of innovative behavior and creativity and innovation (manufacturing companies in Agh Qala Industrial Town)", the research results show that there is a significant relationship between customer-centered and financial performance of the company according to the mediating role of innovative behavior and creativity and innovation. (Seyed Bagheri, 2017)

Sabr Mofaten has conducted a study entitled "The Mediating Role of Innovative Behavior in the Relationship between Perceived Organizational Service-centered and Customer-centered of Staff (Case Study: Bank Rafdin, Central Branch of Iraq)", the innovative behavior required by service organizations, including banks in relation to providing effective services and customer retention. The results showed that the perceived organizational service-centered affects employees' customer-centered in Rafdin Bank of Iraq, and also the innovative behavior of the staff moderates this relationship. As the impact of organizational service-centered on customer-centered in individuals with more innovative behaviors is stronger than those with less innovative behavior. (Sabr Mofaten, 2017)

Shabani and colleagues reviewed the impact of customer participation on new product development: the mediating role of market outcomes. The goal of developing a new product is to meet customer needs, to adapt to business conditions, to cope with rival policies, and to increase customer satisfaction. The findings show that product differentiation variables, competitor orientation, importance of characteristics of brand have a positive and significant effect on customer participation, and the relationship between customer participation and new product development is positive and significant. Also, the market outcomes variable as an intermediate variable affects the relationship between customer participation and new product development in amount of 50\%. Other results indicate that tile and ceramic industries can increase customer satisfaction by interacting with customers and considering their ideas, opinions and needs, and guarantee their success in the market by producing competitive products and gaining more profit. (Shabani et al., 2016)

Sha'bani and Mir Fakhreddini have conducted a study entitled "Customer Participation in New Product Development". The results of the study of the hypotheses show the relationship between customer participation and new product development positive and significant. Another result of the hypothesis that evaluates this relationship through the mediating variable of a new product 
performance shows the positive and significant impact of the customer participation on the new product development. (Shabani and Mirfakhreddini, 2016)

Vazifedust and Memariyan have conducted a study entitled "The relationship between seller's moral conduct and satisfaction, trust and loyalty of insurers in life insurance". The results indicate that moral sales behavior has a direct impact on customer satisfaction and customer trust in the company. Customer satisfaction and customer trust in the company also have a direct impact on customer loyalty. Also, moral sales behavior does not directly affect customer loyalty, but its positive effect on customer loyalty is significant through the mediating variables of customer satisfaction and customer trust in the company. (Vazifedust and Memariyan, 2014)

Bteman and Valentine have conducted a study titled "The impact of the customer's sales in assessing a seller's ethical behavior, trusting the seller, and intention to purchase." In particular, it was examined whether a relational customer-centered (in comparison with functional orientation) could affect the customer's trust and intention to purchase. The data collected from a large sample of experts showed that the rational customer-centered is positively related to the trust to the seller and the purchasing objectives, and trust is positively related to the purchase goals. (Bteman, Valentine, 2015) Wang and colleagues conducted a study entitled "Customer-centered and Creativity". The research was conducted in 1646 manufacturing companies and 686 service companies. Despite the past research, the results of the study indicate that the customer-centered is important in technical companies as well. (Wang et al., 201) Miao and Wang have conducted a research entitled "Different Effects of Functional and Rational Customer-centered on Seller's Creativity". This research examines two types of functional and relational customer-centered and how they impact on creativity, which may depend on underlying factors such as transformational leadership and the workplace. The results indicate that rational customer-centered and functional customer-centered has a positive interactive effect on creativity, and rational customer-centered on creativity has only a positive effect if the sales manager has a higher level of transformational leadership, and in contrast, functional customer-centered has a positive effect when has a higher score from interdependence. Seller's creativity is effective on sales performance when the seller plays a central role in his behavior. Finally, the results show that the effect of functional customercentered and task-oriented on sales function has been completely changed by seller's creativity. (Miao, Wang, 2015)

Kuaster and colleagues have conducted a study on how the impact of sales forces integrity on the success of a new product. By including boundaries of the organization and the foreign market partners, the sales forces are placed in a position to attract insights and unique market prospects. Meanwhile, sales forces have central role to bringing new products to the market as acceptable vendors. Collection data from 609 companies suggests that the use and effectiveness of sales force insights from the new product development point to the integrity of the sales forces, which ultimately improves the position of the new product. The effectiveness of the integrity of the sales force is one of the most probable factors, such as information quality, timing, incentives, nonmonetary sales forces, degree of innovation, and intensity of competition. This study discusses how managers should use the impact of sales force integrity on the success of a new product. (Kuester et al., 2014)

\section{Research hypotheses}

- First hypothesis: A functional customer-centered has a positive and significant impact on seller's creativity. 
- Second hypothesis: A relational customer-centered has a positive and significant impact on seller's creativity.

- The third hypothesis: Seller's creativity has a positive and significant effect on the new product development.

- The fourth hypothesis: The transformational leadership of the sales manager intervenes in the relationship between the functional customer-centered and the seller's creativity.

- Fifth hypothesis: interdependence with the sales unit intervenes in the relationship between relational customer-centered and seller's creativity.

- Sixth hypothesis: The role of customer behaviorism intervenes in the relationship between seller's creativity and the positive points of the new product.

- Seventh hypothesis: Positive points of a new product intervene in the relationship between seller's creativity and new product development.

- Eighth hypothesis: The introduction of a new product of sales force intervenes in the relationship between seller's creativity and new product development.

\section{Methodology}

The research method of the present study is applied objectively, since it is directed towards the scientific use of knowledge. This research is done with the aim to show the relationship between the variables, so this research is a correlation type.

In the stage of collecting information, the regulation of the literature and theoretical foundations of the research, the library method including the study of documents, books, articles in the internal and external journals, theses, databases and the Internet has been used.

The research tool is a questionnaire. The questionnaires used in this study are customer-centered questionnaire (including questions of functional customer-centered, relational customer-centered, sales creativity, interdependence, customer behaviorism, and transformational leadership) and the success of new product development. Researcher-made questionnaires have been designed and their validity has been measured. The number of questions of customer-centered questionnaire is 30 , and the questionnaire of product development success is 36 questions. In order to validate the validity, the view of the supervisor and three sales directors whose employees were present in the research have been used.

To calculate the internal coordination, measuring instrument, such as questionnaires or tests that measure different characteristics is used. Calculation of alpha coefficient was performed using SPSS software. The alpha coefficient of product development successor is 0.95 and customercentered questionnaire is 0.95 , so the research questionnaires have a high validity.

The statistical population of this study is the sales force of pharmaceutical companies in Tehran province. Sample size using the Cochran formula from 51 active pharmaceutical distribution companies in Tehran province is 279 randomly samples.

With the aim of constructing the model, the PLS software has been used; the conventional models in Structural Equation Modeling (SEM) are actually two parts, a measurement model that examines how to explain hidden variables by explicit variables (questions) and a structural model that shows how hidden variables are linked together.

\section{Research findings}

To evaluate the fitting of the structural model of the research, several criteria are used, the first and most significant of which are the significant coefficients or the t-values shown by the execution of the bootstrapping command on the lines of the paths. If its values are more than 1.96, it indicates 
the relationship between the structures and as a result, confirmation of research hypotheses at a confidence level of $95 \%$.

- The first hypothesis: A functional customer-centered has a positive and significant effect on seller's creativity: As shown in Figure 1, the value of t between the two variables of functional customer-centered and seller's creativity is 1.31 and its value is less than 1.96. The functional customer-centered variable has no positive and significant effect on seller's creativity and statistical hypothesis is rejected.

- Second hypothesis: Relational customer-centered has a positive and significant effect on seller's creativity: the value of $\mathrm{t}$ between the two variables of relational customer-centered and the seller's creativity is 3.51 and its value is more than 1.96; therefore, the customer-centered variable has a positive and significant impact on seller's creativity and the statistical hypothesis is confirmed.

- Third hypothesis: Seller's creativity has a positive and significant effect on new product development: the value of $t$ between the two variables of seller's creativity and new product development is 7.36 and its value is more than 1.96; therefore, the seller's creativity variable has a positive and significant impact on new product development and the statistical hypothesis is confirmed.

- Fourth hypothesis: Transformational leadership of the sales manager intervenes in the relationship between the functional customer-centered and the seller's creativity: the value of $t$ between the two variables of functional customer-centered and the seller's creativity with the intervention of the transformational leadership variable is 0.56 and its value is less than 1.96 Therefore, the statistical hypothesis is rejected.

- Fifth hypothesis: Interdependence with the sales unit intervenes in the relationship between the relational customer-centered and the seller's creativity. The value of $t$ between the two variables relational customer-centered and the seller's creativity with the intervention of the interdependent variable is 2.00 and its value is greater than 1.96, so the statistical hypothesis is confirmed.

- Sixth hypothesis: The role of customer behaviorism intervenes in the relationship between seller's creativity and the positive points of a new product: the value of $t$ between the two variables of the positive points of product and the seller's creativity with the intervention of the customer behaviorism variable is 6.18 and its value is more than 1.96, Therefore, the statistical hypothesis is confirmed.

- Seventh hypothesis: The positive points of the new product intervenes in the relationship between seller's creativity and new product development: the value of $t$ between the two variables of the new product development and the seller's creativity with the intervention of the positive points of the product is 3.88 and the value is more than 1.96, Therefore, the statistical hypothesis is confirmed.

- Eight hypothesis: The introduction of new product of sales force intervenes in the relationship between seller's creativity and new product development: the value of t between the two variables of the new product development and the seller's creativity with the intervention of the positive points of the product is 5.63 and the value is more than 1.96, Therefore, the statistical hypothesis is confirmed. 


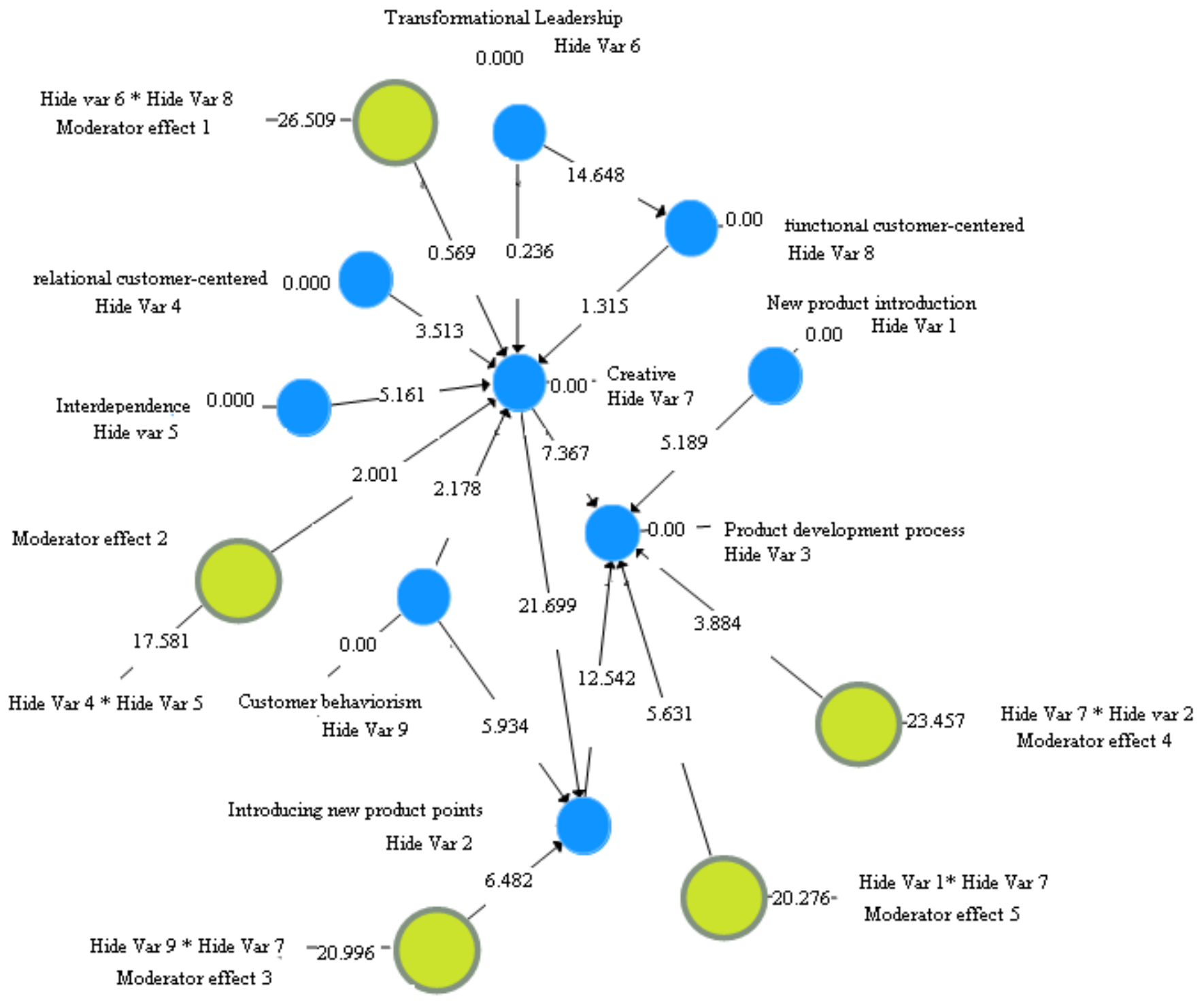

Figure 1: Values to evaluate the structural part of the t-value model

\section{Factor load and $\mathbf{R} 2$ values}

The three values of $0.19,0.33$ and 0.67 as a criterion for weak, moderate and strong R2 and its high value indicate a better fit of the model. The coefficient of determination in Figure 4-11 indicates that the value of $\mathrm{R} 2$ in the functional customer-centered variable is 0.36 , the creativity variable 0.94 , the new product development process variable 0.96 , and the introduction of the positive points of the product is 0.91 , so considering these criteria, appropriateness of fitting of structural model is confirmed. 


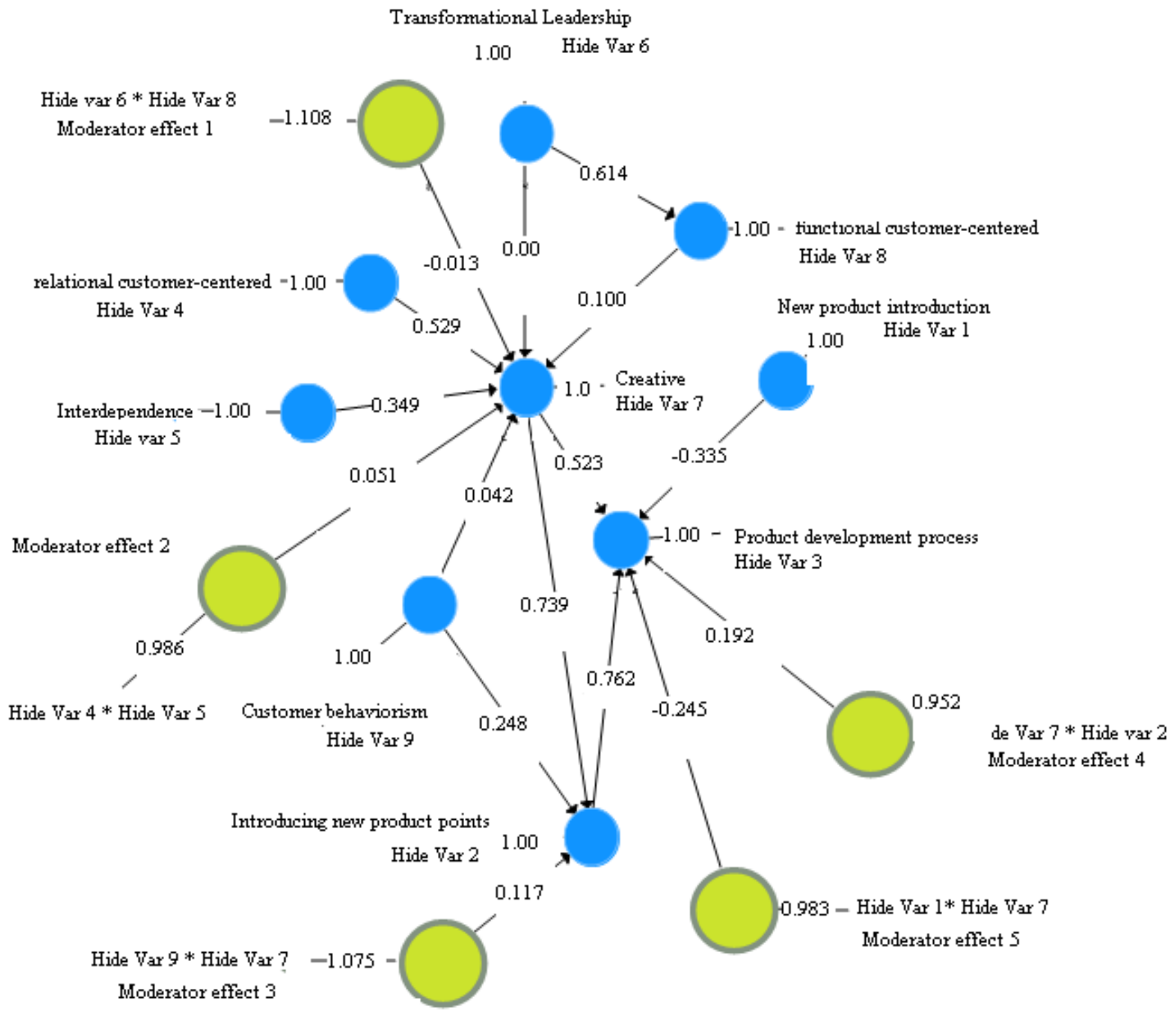

Figure 2: Factor load values and R2

\section{Conclusions and suggestions}

The results of this study are consistent with the results of research of Sha'bani and Mir Fakhredini (2016), Vazifedust and Memarian (2014), Sobhani (2014), Valentin \& Batman (2015), Wang \& Co (2015), Miau \& Wang (2015), Kuastar et al. (2014), Houmberberg et al. (2012), and Liao and Sabramani (2008). According to the findings and results, the following cases are suggested:

- Considering the obvious effect of relational customer-centered on the success of the product development process, it is suggested to consider this issue in industries and to act in order to promote and establish it through training courses; culture in the level of sales staff.

- Applying ways to increase and improve creativity in sales staff through: creativity rewards, positive work environment, support for creative staff and the setting up of creative teams in the organization 
- Training and encouraging sales staff to establish customer behaviorism through: Describing technical concepts by applying examples and providing adequate explanations to customers, using positive sentences, precision in the presentation of product technical information, and honesty.

- Considering the importance of introducing a new product, it is suggested that appropriate measures to be taken including: Match product features to market requirement; Clear explanations and their appropriate location on the product; determining the specific targets for the supply of that product; Potential free advertising capitals; Stimulating the market demand for that product; Timely supply of the product, in order to maximize sales.

- With the aim of introducing positive points in the product of the organization, sales staff should have the knowledge of the same product. (If necessary by using comparison, reveal the product superiority of the organization).

- With the aim of effective product development process, it is suggested that before introducing a new product and investing cash for production, a new product should be tested by a small group of actual consumers by the manufacturing companies. By reviewing the feedback from the product test, manufacturers can make the necessary change to the product, as well as make decisions about how they are officially introduced to the market

\section{References}

Alwani, Mahdi, 1994, General Managment, Publication Ney, Seventh Edition Entrepreneurs Comprehensive Information Portal, 2015, "What Should We Know About the New Product Development".

Khodabakhsh Ghorgani, F, 2010, The Effect of Internal Marketing on Customer Satisfaction among Iranian Insurance Companies Branches in Tehran City, Master's Thesis, Allameh Tabataba'i University, Faculty of Accounting and Management.

Economic world, 2017, An analysis of the state of the pharmaceutical industry in the country

Seyyed Bagheri, Seyyed Shaban, 2017, "Investigating the relationship between customer-centered and financial performance of the company due to the mediating role of innovative behavior and creativity and innovation (manufacturing companies in the industrial town of Agh Ghala), Master's thesis, Institute of Higher Education of Hakim Jarjani

Sha'bani, Akram, Mansouri Mohammad Abadi, Soleiman, Mir Fakhredini, Seyyed Haidar, Safari, Khalil, 2016, The Effect of Customer Contribution on New Product Development: The Intermediary Role of Market Consequences, Journal of Management of Iran, Issue 44, Winter, 2016

Sha'bani, Akram, Mir Fakhreddini, Soleiman, 2016, Investigating the Effect of Customer Participation in New Product Development, Two Quarterly Journal of Business Administration Research, Vol. 8, No. 16, Autumn and Winter, 2016, pp. 140-121.

Abbasi, M. R. Salehi, M., 2011, The Effect of Internal Marketing on Customer-centered in the Insurance Industry, Case Study: Insurance Companies in the City of Tehran, Insurance Policy Quarterly, 102, pp. 176-145

Katler, F and Gary, A, 2010, Marketing Principles, Translation by Bahman Forouzandeh, Amukhte Publications, V10. 
Kordnaeich, A, 2004, Customer-centered: The Success of the Transcendental Organizations. Management Studies Quarterly, No. 43 and 44,183-153.

Sabr Moften, Mahmoud, 2017, Investigating the Mediating Role of Innovative Behavior in the Relationship Between Perceived Organizational Service-centered and Customer-centered of Staff (Case Study: Rafdin Bank of Central Branch of Iraq), Ferdowsi University of Mashhad, MSc Thesis.

Mirzaie Mohammad, 2011, Correction of Organizational Structure in order to promote creativity and innovation with the approach of knowledge-based organizations, national company for refining and distributing oil products in Iran

Nazarmand, A, 2011, Prioritization of factors affecting the customer-centered behavior of employees in insurance companies, Master thesis, Allameh Tabatabaei University.

Vazifedust, Hussein, Memarian, Shima (2014), Investigating the relationship between seller's moral behavior and satisfaction, trust and loyalty of insurers in life insurance, Insurance research journal, Volume 29, Issue 1, Spring 2014, Page 151-127.

Ahn, J.Y., 2003.On the design consepts for CRM system. Indaustrial Management \& Data Systems, 103(5), pp. 324-3.31.

Auh, S. andMenguc, B., 2007.Performance implications of the direct and moderating effects of centralization and formalization on customer orientation. Industrial Marketing Management, pp1034.

Augusto, M. andCoelho, F., 2009. Market orientationand new-to-the-world products: Exploring themoderating effects of innovativeness, competitive strength, and en-vironmental forces. IndustrialMarketing Managemen, 38(1), pp. 94-108.

Bteman, connie, Valentine,Sean (2015), The impact of salesperson customer orientation on the evaluation of a salesperson's ethical treatment, trust in the salesperson, and intentions to purchase, Journal of Personal Selling \& Sales Management, Volume 35, 2015.

Bose, R., 2002. Customer relationship management: Key components for IT success.Indaustrial Management \& Data Systems, 102 (2), PP. 89-97.

Brown, T., Mown, J, Donavan, D.andLicata, J., 2002.The customer orientation of service workers: Personality trait effects on self and supervisor performance rating.Journal of Marketing Research, 39(1), pp.110-119.

Duckett, H, and Macfarlane, E. (2003). Emotional intelligence and transformational leadership in retailing. Leadership \& Organization Development Journal, Vol. 24, pp. 309-317.

Kim, J.Y., Moon, J., Han, D. and Tikoo, S., 2004.Perception of justice and employee willingness to engage in customer -oriented behavior. Journal of Services Marketing, 18(4), pp.267-275.

Kuester, Sabine, Homborg, Chiristian, Hildesheim, Andreas (2014), The Catbird seat of the sales force: How sales force integration lead to new product success, International Jouranal of rsearch in Marketing, 17 October 2014.

Mandell, B. and Pherwani, S. (2003). Relationship between emotional intelligence and transfortional leadership style: a gender coperation. Journal of Business and Psychology, Vol. 17, pp. 387-404. 
Miao, C Fred, Wang, Guangping (2016), the differential effects of functional vis-à-vis relation customer orientation salesperson creativity, Journal of Business Research, 25 May 2016.

Sarros, J. C. and Santora, J. C. (2001). The transformational-transactional leadership in model. Leadership \& Organization Development Journal. Vol. 22, pp. 383-393.

Strong, C.A. and Harris, L.C., 2004. The drivers of customer orientation: An exploration of relational, human resource and procedural tactics. Journal of Strategic Marketing, 12 (3), pp. 183-204.

Wang, Qiang, Zhao, Xiande, Voss, Chris (2015), Customer orientation and innovation: A comparative study of manufacturing and service firms, https://doi.org/10.1016/j.ijpe.2015.08.029Get rights and content. 